\title{
Synthetic Analogs of Green Tea Polyphenols as Proteasome Inhibitors
}

\author{
David M. Smith' ${ }^{1}$, Zhigang Wang ${ }^{2}$, Aslamuzzaman Kazi ${ }^{1}$, Lian-hai Li ${ }^{2}$, \\ Tak-Hang Chan ${ }^{2}$, and Q. Ping Dou ${ }^{1}$ \\ ${ }^{1}$ Drug Discovery Program, H. Lee Moffitt Cancer Center \& Research Institute, Departments of \\ Interdisciplinary Oncology and Biochemistry \& Molecular Biology, College of Medicine, \\ University of South Florida, Tampa, FL, USA \\ ${ }^{2}$ Department of Chemistry, McGill University, Montreal, Quebec, CA \\ Communicated by A. Pardee. Accepted June 5, 2002
}

\begin{abstract}
Background: Animal, epidemiological and clinical studies have demonstrated the anti-tumor activity of pharmacological proteasome inhibitors and the cancer-preventive effects of green tea consumption. Previously, one of our laboratories reported that natural ester bond-containing green tea polyphenols (GTPs), such as (-)-epigallocatechin-3-gallate [(-)-EGCG] and (-)-gallocatechin-3-gallate [(-)-GCG], are potent and specific proteasome inhibitors. Another of our groups, for the first time, was able to enantioselectively synthesize (-)-EGCG as well as other analogs of this natural GTP. Our interest in designing and developing novel synthetic GTPs as proteasome inhibitors and potential cancer-preventive agents prompted our current study.

Materials and Methods: GTP analogs, (+)-EGCG, (+)GCG, and a fully benzyl-protected (+)-EGCG [Bn-(+)EGCG], were prepared by enantioselective synthesis. Inhibition of the proteasome or calpain (as a control) activities under cell-free conditions were measured by fluorogenic substrate assay. Inhibition of intact tumor cell proteasome activity was measured by accumulation of some proteasome target proteins (p27, I $\kappa \mathrm{B}-\alpha$ and Bax) using Western blot analysis. Inhibition of tumor cell
\end{abstract}

proliferation and induction of apoptosis by synthetic GTPs were determined by $G_{1}$ arrest and caspase activation, respectively. Finally, inhibition of the transforming activity of human prostate cancer cells by synthetic GTPs was measured by a colony formation assay.

Results: (+)-EGCG and (+)-GCG potently and specifically inhibit the chymotrypsin-like activity of purified $20 \mathrm{~S}$ proteasome and the $26 \mathrm{~S}$ proteasome in tumor cell lysates, while Bn-(+)-EGCG does not. Treatment of leukemic Jurkat $\mathrm{T}$ or prostate cancer LNCaP cells with either $(+)$-EGCG or $(+)$-GCG accumulated p27 and $\mathrm{I} \kappa \mathrm{B}-\alpha$ proteins, associated with an increased $G_{1}$ population. (+)-EGCG treatment also accumulated the pro-apoptotic Bax protein and induced apoptosis in LNCaP cells expressing high basal levels of Bax, but not prostate cancer DU-145 cells with low Bax expression. Finally, synthetic GTPs significantly inhibited colony formation by LNCaP cancer cells.

Conclusions: Enantiomeric analogs of natural GTPs, $(+)$-EGCG and (+)-GCG, are able to potently and specifically inhibit the proteasome both, in vitro and in vivo, while protection of the hydroxyl groups on (+)-EGCG renders the compound completely inactive.

\section{Introduction}

Several epidemiological studies have suggested that green tea consumption may be associated with prevention of cancer or inhibition of cancer reoccurrence (1-6). Other studies have also demonstrated that green tea can inhibit tumor growth and development in several animal models (7-10). The responsible molecular mechanism(s) is/are unknown, but thought to be related to inhibition of several tumor-promoting proteins, such as epidermal growth factor receptor (11), mitogen activated protein kinase $(12,13)$, telomerase (14), and the proteasome (15), a large multi-catalytic protease. Extracts from green tea contain several polyphenols that possess the primary biological activities of tea (16-20). It has been found that (-)-EGCG

Address correspondence and reprint requests to: Q. Ping Dou, Drug Discovery Program, H. Lee Moffitt Cancer Center and Research Institute, MRC 1259C, 12902 Magnolia Dr., Tampa, FL 33612-9497. Phone: 813-632-1437, fax: 813-979-6748, e-mail: douqp@moffitt.usf.edu. is the most active component responsible for the aforementioned mechanisms in these pre-clinical studies. In contrast, very little information about tea clinical trials is currently available. A recently completed phase I clinical trial using green tea extract has concluded that a dose of green tea equivalent to 7-8 cups could be taken safely, three times a day, for at least six months $(21,22)$. Another phase I pharmacokinetic study has found that the EGCG and tea polyphenol formulations containing the same amount of EGCG resulted in similar plasma EGCG levels (23).

It has been shown recently that the proteasome is essential for tumor cell survival, and pharmacological inhibition of the proteasome in various cancer cell models can induce tumor cell growth arrest and/or apoptosis (24-30). In addition, proteasome inhibitors are able to inhibit human tumor growth in various animal models (31-33). It has been shown that proteasome-mediated degradation of important cell cycle regulators plays an essential role in cell cycle progression. One such proteasome 
target protein is cyclin-dependent kinase inhibitor p27. Accumulation of p27 by proteasome inhibition is associated with cell cycle arrest $(25,32)$. I $\kappa \mathrm{B}-\alpha$, another important proteasome target protein, is an endogenous inhibitor of transcription factor $\mathrm{NF} \kappa \mathrm{B}$. $\mathrm{I} \kappa \mathrm{B}-\alpha$ inhibits NF $\kappa \mathrm{B}$ by binding to it in the cytosol and preventing its translocation to the nucleus where NF $\kappa$ B elicits its transcriptional control of several anti-apoptotic genes $(34,35)$. Expression of $\mathrm{I} \kappa \mathrm{B}-\alpha$ protein is regulated at the level of degradation by the proteasome (36). Therefore, treatment with a proteasome inhibitor is also able to accumulate $\mathrm{I} \kappa \mathrm{B}-\alpha$ protein levels $(15,26,30,36,37)$.

Bax, a Bcl-2 family member, is an important mitochondrial associated proapoptotic protein. It has been shown that Bax plays a role in regulating the release of cytochrome $\mathrm{C}$ from the mitochondria to the cytosol during the initiation of apoptosis (38). This released cytosolic cytochrome $\mathrm{C}$ is able to initiate the caspase cascade (38). Bax has also been shown to be regulated by ubiquitin/proteasomemediated degradation $(28,39)$. Indeed, inhibition of the proteasome accumulates Bax in mitochondria and induces tumor cell apoptosis (28).

Previously, we reported that ester bond-containing tea polyphenols, such as (-)-EGCG, potently and specifically inhibit chymotrypsin-like activity of the proteasome in vitro $\left(\mathrm{IC}_{50} 86-194 \mathrm{nM}\right)$ and in vivo $(1-10 \mu \mathrm{M})$ at the concentrations found in the serum of green tea drinkers (15). Atomic orbital energy analyses and high-performance liquid chromatography suggest that the carbon of the polyphenol ester bond is essential for targeting and thereby inhibiting the proteasome in cancer cells. This inhibition of the proteasome by (-)-EGCG in several tumor and transformed cell lines results in accumulation of $\mathrm{p} 27^{\mathrm{Kip} 1}$ and $\mathrm{I} \kappa \mathrm{B}-\alpha$, followed by $\mathrm{G}_{1}$ arrest. Furthermore, compared to their simian virus-transformed counterpart, the parental normal human fibroblasts were much more resistant to (-)-EGCGinduced $\mathrm{p} 27^{\mathrm{Kip} 1}$ protein accumulation and $G_{1}$ arrest (15).

Until recently, all pre-clinical and clinical studies were conducted with GTPs extracted or purified from green tea leaves. Synthesis of EGCG has been long awaited by the tea research field so that mechanistic elucidation of EGCG and its activities, by structural manipulation, might be evaluated. Due to the past unavailability of GTP analogs, at present there is no literature describing the usage of synthetic tea polyphenols and analogs thereof in any form of pre-clinical research. Only recently have synthetic forms of GTPs including (-)-EGCG and its synthetic analogs thereof (including $(+)$-EGCG), been created by one of our groups (40). Here we report, for the first time, synthetic GTPs exhibit proteasome-inhibitory activity in vitro and in vivo. In addition, these synthetic GTPs are able to inhibit cell growth, induce apoptosis, and suppress the transforming activity in human cancer cells.

\section{Materials and Methods Materials}

Highly purified tea polyphenols (-)-EGCG (>95\%) and $(-)-$ GCG $(>98 \%)$ were purchased from Sigma (St. Louis, MO). (+)-EGCG, Bn-(+)-EGCG, (-)-GCG and $(+)-G C G$ were prepared by enantioselective synthesis (see below). The synthetic and the commercial (-)-GCG gave identical proteasome-inhibitory properties and therefore only the commercial (-)-GCG was used in the experiments presented in this manuscript. Purified 20S proteasome (Methanosarcina thermophile, Recombinant, E. coli) and purified calpain I (Human Erythrocytes) were purchased from Calbiochem (La Jolla, CA). Fluorogenic peptide substrates Suc-LeuLeu-Val-Tyr-AMC (for the proteasomal chymotrypsinlike activity), Suc-Leu-Tyr-AMC (for the calpain I activity), and Ac-DEVD-AMC (the specific caspase-3 substrate) were also obtained from Calbiochem (La Jolla, CA), and Z-Gly-Gly-Arg-AMC (for the proteasomal trypsin-like activity) was from Bachem (King of Prussia, PA). Monoclonal antibody to p27 ${ }^{\mathrm{Kip}}$ was purchased from PharMingen (San Diego, CA); polyclonal antibodies to $\mathrm{I} \kappa \mathrm{B}-\alpha$, $\mathrm{Bax}(\mathrm{N}-20)$, and actin were from Santa Cruz Biotechnology Inc. (Santa Cruz, CA). Polyclonal antibodies to human PARP were from Boehringer Mannheim (Indianapolis, IN).

\section{Enantioseletive Synthesis of GTPs}

$(+)$-EGCG and the fully benzyl protected (+)-EGCG [Bn(+)-EGCG] were prepared according to our previously reported procedures (40). Preparation of $(+)-G C G$. To a solution of $(+)-[2 R, 35]-5,7-b i s$ (benzyloxy)-2-[3,4,5-tris(benzyloxy)phenyl]chroman3-ol (35) (145 mg, $190 \mu \mathrm{mol}, 1.0$ equiv) in $\mathrm{CH}_{2} \mathrm{Cl}_{2}$ (15 mL) was added dimethylaminopyridine $(58 \mathrm{mg}$, $470 \mu \mathrm{M}, 2.5$ equiv) under $\mathrm{N}_{2}$. The solution was cooled to $0^{\circ} \mathrm{C}$, and 3,4,5-tris(benzyloxy)benzoic acid chloride (131 mg, $285 \mu \mathrm{mol}, 1.5$ equiv) was added. The mixture was allowed to warm to room temperature and stirred for $16 \mathrm{~h}$. Saturated $\mathrm{NaHCO}_{3}$ aqueous solution $(20 \mathrm{~mL})$ was added and the mixture stirred at room temperature for an additional $1 \mathrm{~h}$. The layers were separated, and the aqueous layer was extracted with EtOAc $(4 \times 25 \mathrm{~mL})$. The combined organic phase was washed with brine $(20 \mathrm{~mL})$, dried over $\mathrm{Na}_{2} \mathrm{SO}_{4}$, and was concentrated by rotary evaporator and vacuum drying to give crude product which was purified by silica gel chromatography $\left(\mathrm{C}_{6} \mathrm{H}_{6} / \mathrm{EtOAc}=100 / 1\right)$ to afford pure product $195 \mathrm{mg}(87 \%)$ of the fully benzyl protected gallate ester as a white solid. $[\alpha]_{\mathrm{D}}=22.17$ $\left(\mathrm{cl} .09, \mathrm{CHCl}_{3}\right) ;{ }^{1} \mathrm{H}$ NMR (300 MHz, $\left.\mathrm{CDCl}_{3}\right): 7.31$ (m, $42 \mathrm{H}), 6.70(\mathrm{~s}, 2 \mathrm{H}), 6.32(\mathrm{~s}, 1 \mathrm{H}), 6.31(\mathrm{~s}, 1 \mathrm{H}), 5.48(\mathrm{~m}$, $1 \mathrm{H}), 5.12(\mathrm{~m}, 1 \mathrm{H}), 5.01(\mathrm{~m}, 16 \mathrm{H}), 2.99(\mathrm{dd}, \mathrm{J}=16.8$, $5.2,1 \mathrm{H}), 2.84(\mathrm{dd}, \mathrm{J}=16.8,10.2,1 \mathrm{H}) ; 13 \mathrm{C}$ NMR $(75$ $\left.\mathrm{MHz}, \mathrm{CDCl}_{3}\right): 165.07,158.92,157.64,154.78,152.86$, $152.39,142.54,138.36,137.66,137.33,136.76,136.71$, $136.47,133.38,128.59,128.53,128.48,128.43,128.39$, $128.25,128.15,128.08,128.02,127.98,127.94,127.90$, $127.81,127.75,127.62,127.50,127.48,127.21,124.92$, 
109.06, 106.23, 101.29, 94.26, 93.78, 78.41, 75.10, $75.05,71.22,71.13,70.09,69.90,69.80,24.00$.

To a solution of the fullyl benzyl protected gallate ester $(100 \mathrm{mg}, 84.8 \mu \mathrm{mol})$ obtained above in $\mathrm{MeOH} / \mathrm{THF}(10 / 10 \mathrm{~mL})$ was added $\mathrm{Pd}(\mathrm{OH})_{2}(105 \mathrm{mg}$, $20 \%$ on carbon). The mixture was stirred at room temperature under $\mathrm{H}_{2}$ and monitored by TLC. When the starting material was consumed (in about $4 \mathrm{~h}$ ), the mixture was filtered through cotton to remove the catalyst, and eluted with acetone $(5.0 \mathrm{~mL})$. The combined eluate was concentrated by rotary evaporator and vacuum drying to give the crude product which was purified by silica gel chromatography $\left(\mathrm{EtOAc} / \mathrm{CH}_{2} \mathrm{Cl}_{2}=2.5 / 1\right)$ to afford the pure (+)-GCG, $28.6 \mathrm{mg}(74 \%)$ as a white solid. $[\alpha]_{\mathrm{D}}=11.78$ (c 0.78, THF); ${ }^{1} \mathrm{H}$ NMR (300 MHz, acetone-d/D ${ }_{2} \mathrm{O}=$ 2/1): $6.94(\mathrm{~s}, 2 \mathrm{H}), 6.44(\mathrm{~s}, 2 \mathrm{H}), 5.98(\mathrm{~d}, \mathrm{~J}=2.5,1 \mathrm{H})$, $5.88(\mathrm{~d}, \mathrm{~J}=2.5,1 \mathrm{H}), 5.23(\mathrm{q}, \mathrm{J}=6.6,1 \mathrm{H}), 4.93$ $(\mathrm{d}, \mathrm{J}=6.6,1 \mathrm{H}), 3.00(\mathrm{dd}, \mathrm{J}=16.5,5.2,1 \mathrm{H}), 2.61$ $(\mathrm{dd}, \mathrm{J}=16.5,6.6,1 \mathrm{H}) ;{ }^{13} \mathrm{C} \mathrm{NMR}\left(75 \mathrm{MHz}, \mathrm{CDCl}_{3}\right)$ : $166.25,156.73,156.33,155.24,145.66,145.22,138.69$, 132.97, 129.64, 120.34, 109.47, 106.07, 98.70, 95.87, $94.81,78.30,70.27,24.25$. The compound had identical NMR spectra as the commercially available natural (-)-GCG (Sigma, $[\alpha]_{\mathrm{D}}=-12.44$ (c 0.8 , THF).

\section{Cell Culture and Cell Extract Preparation}

Human Jurkat T and prostate cancer (LNCaP, DU-145) cells were cultured in RPMI 1640, supplemented with $10 \%$ fetal calf serum, 100 units $/ \mathrm{ml}$ of penicillin and $100 \mu \mathrm{g} / \mathrm{ml}$ of streptomycin. All cells were maintained in a $5 \% \mathrm{CO}_{2}$ atmosphere at $37^{\circ} \mathrm{C}$. A whole cell extract was prepared as described previously (25). Briefly, cells were harvested, washed with PBS twice and homogenized in a lysis buffer $(50 \mathrm{mM}$ Tris- $\mathrm{HCl}, \mathrm{pH} \mathrm{8.0,}$ 5 mM EDTA, $150 \mathrm{mM} \mathrm{NaCl}, 0.5 \% \mathrm{NP}-40,0.5 \mathrm{mM}$ PMSF, and $0.5 \mathrm{mM}$ dithiothreital) for $30 \mathrm{~min}$ at $4^{\circ} \mathrm{C}$. After that, the lysates were centrifuged at $10,000 \times \mathrm{g}$ for $30 \mathrm{~min}$ and the supernatants were collected as whole cell extracts.

\section{Inhibition of Purified 20S Proteasome Activity by Synthetic Tea Polyphenols}

The chymotrypsin-like activity of purified $20 \mathrm{~S}$ proteasome was measured as follows. Briefly, $0.5 \mu \mathrm{g}$ of purified $20 \mathrm{~S}$ proteasome was incubated with $20 \mu \mathrm{M}$ of a fluorogenic peptide substrate, Suc-Leu-Leu-ValTyr-AMC for $30 \mathrm{~min}$ at $37^{\circ} \mathrm{C}$ in $100 \mu$ l of assay buffer (50 mM Tris- $\mathrm{HCl}, \mathrm{pH} 7.5$ ), with or without a synthetic or natural tea polyphenol. After incubation, production of hydrolyzed 7-amido-4-methyl-coumarin (AMC) groups were measured using a multi-well plate VersaFluor $^{\mathrm{TM}}$ Fluorometer with an excitation filter of $380 \mathrm{~nm}$ and an emission filter of $460 \mathrm{~nm}$ (Bio-Rad).

\section{Inhibition of the Proteasome Activity in Whole Cell} Extracts by Synthetic Tea Polyphenols

A whole cell extract (10 $\mu \mathrm{g})$ of Jurkat $\mathrm{T}$ cells was incubated for $60 \mathrm{~min}$ at $37^{\circ} \mathrm{C}$ with $20 \mu \mathrm{M}$ of the fluorogenic peptide substrates for various activities of the proteasome, Suc-Leu-Leu-Val-Tyr-AMC and Z-Gly-Gly-Arg-AMC, in $100 \mu$ l of the assay buffer with or without a synthetic or natural tea polyphenol. The hydrolyzed AMCs were quantified as described above.

\section{Assay for Calpain I Activity}

To measure calpain I activity, $3 \mu \mathrm{g}$ purified calpain I was incubated with $40 \mu \mathrm{M}$ of a fluorogenic peptide calpain substrate, Suc-Leu-Tyr-AMC, for $30 \mathrm{~min}$ at $37^{\circ} \mathrm{C}$ in $100 \mu \mathrm{l}$ of assay buffer $(50 \mathrm{mM}$ Tris- $\mathrm{HCl}, \mathrm{pH}$ 7.5, $50 \mathrm{mM} \mathrm{NaCl}, 1 \mathrm{mM}$ EDTA, $1 \mathrm{mM}$ EGTA, $5 \mathrm{mM}$ $\beta$-Mercaptoethanol, $5 \mathrm{mM} \mathrm{CaCl}{ }_{2}$, and $0.1 \%$ CHAPS), with or without a synthetic or natural tea polyphenol, and the hydrolyzed AMCs were quantified as described above.

\section{Assay for Caspase 3 Activity}

Cell-free caspase 3 activity was determined by measuring the cleavage of AMC groups from a caspase 3 specific substrate (Ac-DEVD-AMC). Briefly, a prepared protein extract $(20 \mu \mathrm{g})$ was incubated in a buffer containing $50 \mathrm{mM}$ Tris/pH 7.5 along with the caspase substrate at $20 \mu \mathrm{M}$ in a 96 well plate. The reaction mixture was incubated at $37^{\circ} \mathrm{C}$ for $1 \mathrm{~h}$. After incubation, the liberated florescent AMC groups were quantified as described above.

\section{Western Blot Analysis}

Jurkat T, LNCaP or DU-145 cells were treated with various concentrations of synthetic or natural tea polyphenols for indicated hours (see figure legends). This was followed by preparation of whole cell extracts. The enhanced chemiluminescence (ECL) Western Blot analysis was then performed using specific antibodies to $\mathrm{p} 27^{\mathrm{Kip}}$, I $\kappa \mathrm{B}-\alpha$, PARP, Bax, or actin, as described previously (25).

\section{Flow Cytometry}

Cell cycle analysis based on DNA content was performed as follows. At each time point, cells were harvested, counted, and washed twice with PBS. Cells $\left(5 \times 10^{6}\right)$ were suspended in $0.5 \mathrm{ml}$ PBS, fixed in $5 \mathrm{ml}$ of $70 \%$ ethanol for at least $2 \mathrm{~h}$ at $-20^{\circ} \mathrm{C}$, centrifuged, resuspended again in $1 \mathrm{ml}$ of propidium iodide staining solution (50 $\mathrm{g}$ gropidium iodide, 100 units RNase A and $1 \mathrm{mg}$ glucose per ml PBS), and incubated at room temperature for $30 \mathrm{~min}$. The cells were then analyzed with FACScan (Becton Dickinson Immunocytometry, CA) and ModFit LT cell cycle analysis software (Verity Software, Topsham, ME). The cell cycle distribution is presented as the percentage of cells containing $G_{1}, S, G_{2}$ and M DNA content as judged by propidium iodide staining.

\section{Soft Agar Assay}

The soft agar assay was prepared as described previously with a few modifications (41). In brief, in a six-well plate, a bottom feeder layer (0.6\% agar) 
was prepared with DMEM media containing $10 \%$ fetal bovine serum and $1 \%$ penicillin/streptomycin. A top layer was prepared with $0.3 \%$ agar and the same media as described above containing $2 \times 10^{4}$ prostate cancer LNCaP cells and each respective GTP compound. Plates were incubated at $37^{\circ} \mathrm{C}$ in $5 \%$ $\mathrm{CO}_{2}$ in a humidified incubator for two weeks. The plates were then imaged and the number of colonies were quantified by Quantity one v.4.0.3 software (BioRad, Hercules, CA).

\section{Results}

Synthetic GTPs Potently and Selectively Inhibit the

Proteasomal Chymotrypsin-like Activity Under Cell-free Conditions

We have previously demonstrated that naturally occurring green tea polyphenols, which contain esterbonds, can inhibit the chymotrypsin-like activity of the proteasome (15). We now have synthesized novel analogs of the naturally occurring tea polyphenols
(40 and see Materials and Methods), and have tested their inhibitory potencies against the proteasome. Two analogs of (-)-EGCG were synthesized. The first analog, (+)-EGCG, was the enantiomer (mirror image) of the natural (-)-EGCG, having the 2R, 3R configuration instead of the natural $2 \mathrm{~S}$, $3 \mathrm{~S}$ configuration. [see Fig. 1, (-)-EGCG vs. (+)-EGCG]. The second analog, Bn- $(+)-E G C G$, was synthesized with all eight hydroxyls protected by benzyl groups. This should eliminate any hydrogen bonding created by the hydroxyls in (+)-EGCG while maintaining the integrity of the ester bond. In addition the enantiomer of the natural (-)-GCG was also synthesized, giving (+)-GCG with the 2R, 3S configuration [see Fig. 1., (-)-GCG and (+)-GCG].

We first determined the ability of each purified synthetic GTP analog to inhibit the chymotrypsinlike activity of purified $20 \mathrm{~S}$ proteasome, using the natural GTPs for comparison. In this experiment, the synthetic (+)-EGCG at $1 \mu \mathrm{M}$ inhibited $86 \%$ of the proteasomal activity, similar to that of its natural<smiles>O=C(O[C@H]1Cc2c(O)cc(O)cc2O[C@H]1c1cc(O)c(O)c(O)c1)c1cc(O)c(O)c(O)c1</smiles>

(-)-Epigallocatechin gallate [(-)-EGCG]<smiles>O=C(OC1Cc2c(O)cc(O)cc2OC1c1cc(O)c(O)c(O)c1)c1cc(O)c(O)c(O)c1</smiles>

$(+)$-Epigallocatechin gallate $[(+)-\mathrm{EGCG}]$

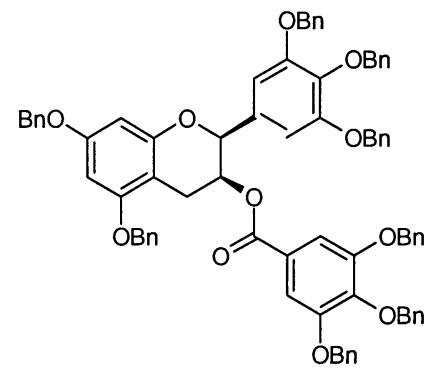

$\mathrm{Bn}-(+)$-Epigallocatechin gallate<smiles>O=C(O[C@H]1Cc2c(O)cc(O)cc2OC1c1cc(O)c(O)c(O)c1)c1cc(O)c(O)c(O)c1</smiles>

(-)-Gallocatechin gallate [(-)-GCG]
[Bn-(+)-EGCG]<smiles>O=C(O[C@H]1Cc2c(O)cc(O)cc2O[C@H]1c1cc(O)c(O)c(O)c1)c1cc(O)c(O)c(O)c1</smiles>

$(+)$-Gallocatechin gallate [(+)-GCG]
Fig. 1. Structures of synthetic and natural green tea polyphenols (GTPs). The two natural GTP compounds are (-)Epigallocatechin gallate and (-)-Gallocatechin gallate, and the three synthetic analogs are $(+)$-Epigallocatechin gallate, $(+)$-BnEpigallocatechin gallate, and (+)Gallocatechin gallate. 
counterpart, (-)-EGCG (Fig. 2A). However, the benzyl-protected compound, Bn-(+)-EGCG, did not significantly inhibit the proteasome activity even at $10 \mu \mathrm{M}$ concentrations, demonstrating the requirement of one or more hydroxyl groups for the proteasomeinhibitory activity of EGCG. The synthetic (+)-GCG was found to inhibit $70 \%$ of the proteasomal activity at $1 \mu \mathrm{M}$, similar to the natural (-)-GCG (Fig. 2A). It is also worthy to note that both forms of EGCG are more potent than the two GCG analogs. As a control in this experiment, a well-known tripeptidyl proteasome inhibitor LLnL at 1 and $10 \mu \mathrm{M}$ inhibited 20 and $70 \%$ proteasomal activity, respectively (Fig. $2 \mathrm{~A}$ ).

To further determine the proteasome-inhibitory activities of the synthetic GTP analogs, multiple concentrations of each GTP was used in order to measure their one-half maximal inhibition values $\left(\mathrm{IC}_{50} \mathrm{~S}\right)$. An $\mathrm{IC}_{50}$ of $210 \mathrm{nM}$ was found for the synthetic $(+)$ EGCG, similar to the control (-)-EGCG (Fig. 2B). In addition, the $(+)$-GCG compound, similar to the natural (-)-GCG, produced an $\mathrm{IC}_{50}$ value of $410 \mathrm{nM}$, nearly twice that of (+)-EGCG (Fig. 2B-C).

To determine the specificity of the synthetic GTP analogs, we tested their effects on the chymotrypsinlike and trypsin-like activities of the $26 \mathrm{~S}$ proteasome in a Jurkat cell lysate. Similar to inhibition of the purified 20S proteasome, the synthetic (+)-EGCG at $10 \mu \mathrm{M}$ inhibited $76 \%$ of the chymotrypsin-like activity of $26 \mathrm{~S}$ proteasome in cell lysates (Fig. 3A). In contrast, the Bn-(+)-EGCG analog could not inhibit the proteasomal chymotrypsin activity at all. (+)GCG at the same concentration inhibited $\sim 50 \%$ of the chymotrypsin-like activity. The potencies of $(+)$ EGCG and $(+)$-GCG were similar to those of their natural partners, respectively. However, none of the synthetic or natural GTPs could significantly inhibit the proteasomal trypsin-like activity in the Jurkat cell extract (Fig. 3B). Furthermore, none of the synthetic or control natural compounds could inhibit more than $15 \%$ of activity of a purified calpain enzyme (Fig. 3C). These data strongly suggest that the synthetic GTPs with ester bonds selectively inhibit the chymotrypsin-like activity of the proteasome.

\section{Accumulation of Proteasome Target Proteins p27 and IKB- $\alpha$ and Induction of Tumor Cell $G_{1}$ Arrest by Synthetic GTPS}

Having discovered that the synthetic GTP analogs are potent and specific inhibitors of the proteasomal chymotrypsin-like activity in vitro (Figs. 2, 3), we then determined whether the synthetic compounds could also be effective in inhibiting intact tumor cell

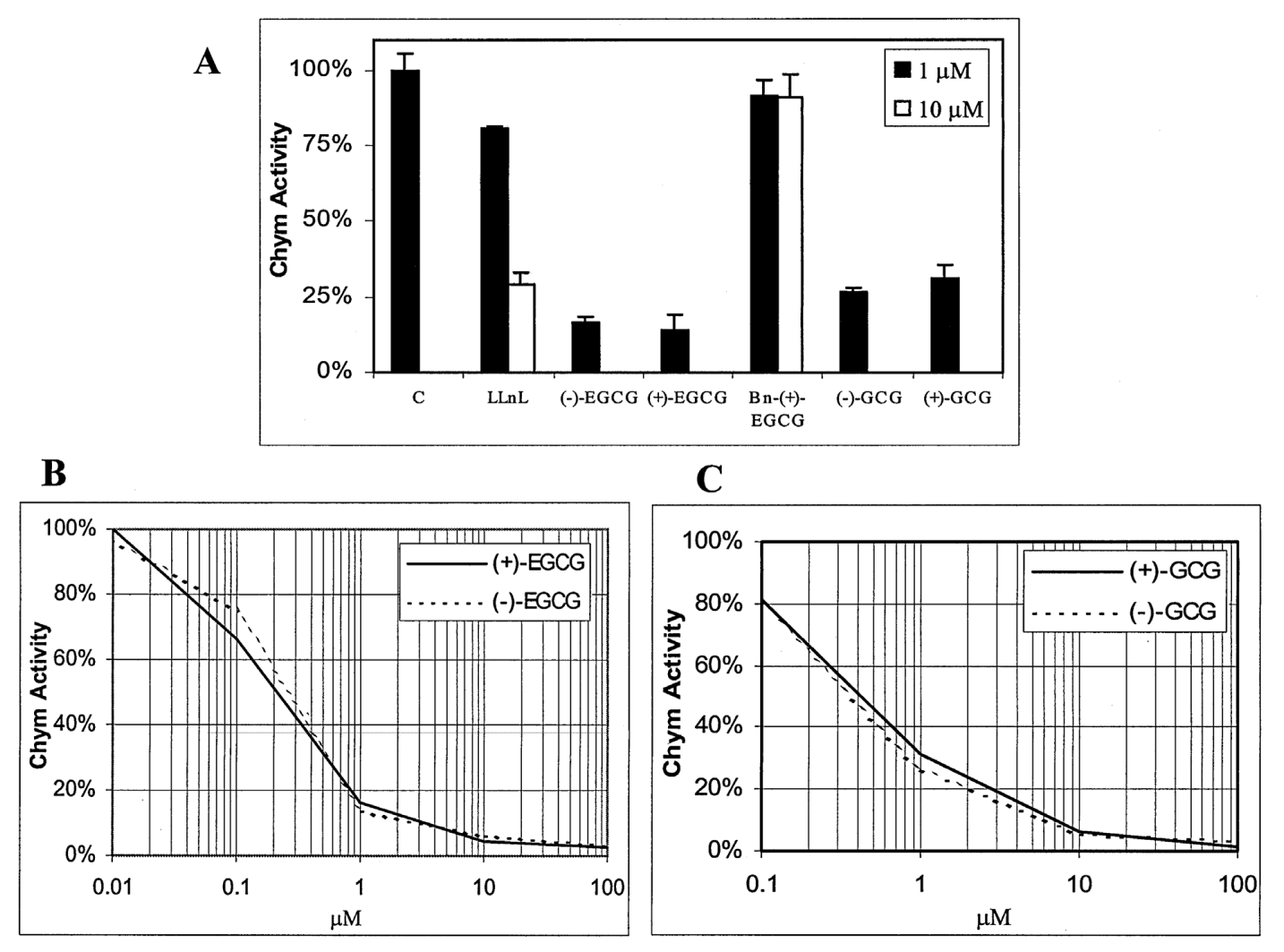

Fig. 2. Inhibition of purified 20 s proteasome by synthetic and natural GTPs. Inhibition of chymotrypsin-like activity of the purified 20S proteasome was measured as described in Materials and Methods (A). LLnL was chosen as a positive control. Dosedependant inhibition of purified 20S proteasome by (+)-EGCG and (-)-EGCG (B), or (+)-GCG and (-)-GCG (C) is graphed on a log plot. All values are means of independent triplicate experiments. Error bars denote standard deviations (error bars were not included on $\mathbf{B}$ and $\mathbf{C}$ for clarity of presentation). 


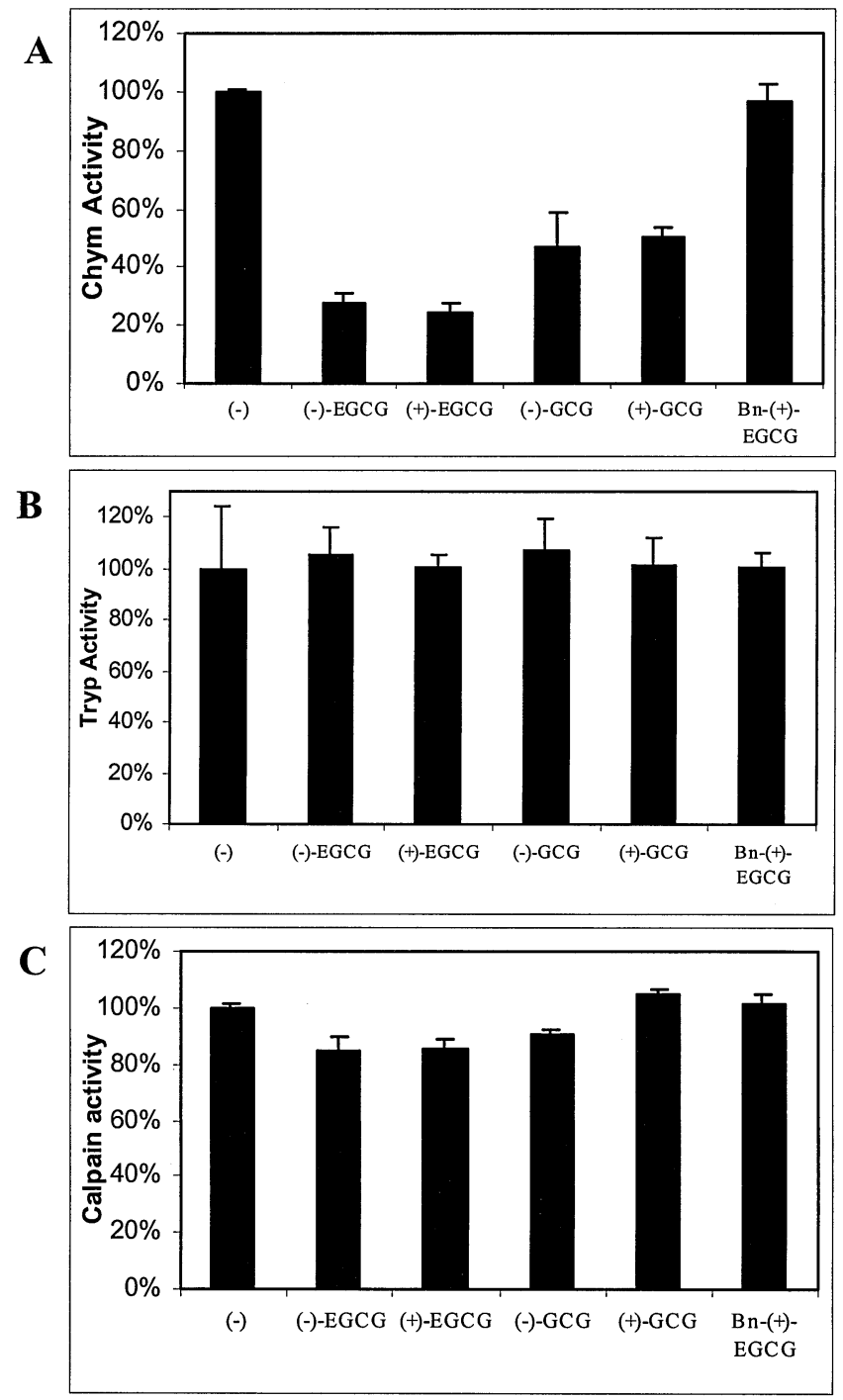

Fig. 3. Specific inhibition of proteasome activity by synthetic GTPs. A Jurkat cell extract was incubated for $1 \mathrm{hr}$ with various fluorogenic peptide substrates for the proteasomal chymotrypsin-like (A) or trypsin-like activity (B), or a purified calpain I was incubated for $1 \mathrm{hr}$ with a fluorogenic calpain substrate (C), in the absence or presence of $10 \mu \mathrm{M}$ GTPs, as indicated, followed by measurement of free AMC groups as described in Materials and Methods. Values are mean triplicates and error bars denote standard deviations.

proteasome activity. Because inhibition of the proteasome activity in tumor cells would result in increased levels of proteasome target proteins, we measured levels of p27 and $\mathrm{I} \kappa \mathrm{B}-\alpha$ proteins by Western blot assay in Jurkat $\mathrm{T}$ cells treated with each GTP. After a $12 \mathrm{~h}$ treatment, (+)-EGCG at $10 \mu \mathrm{M}$ accumulated p27 and $\mathrm{I} \kappa \mathrm{B}-\alpha$ levels by 3.5- and 3.1-fold, respectively (Fig. 4A). In comparison, the natural (-)-EGCG accumulated p27 and I $\kappa$ B- $\alpha$, to a slightly lesser extent, by 2.7- and 2.1-fold, respectively (Fig. 4A). In addition, synthetic (+)-GCG increased p27 and I $\kappa$ B- $\alpha$ levels by 3.7- and 3.3-fold, respectively, similar to the results from (-)-GCG treatment.
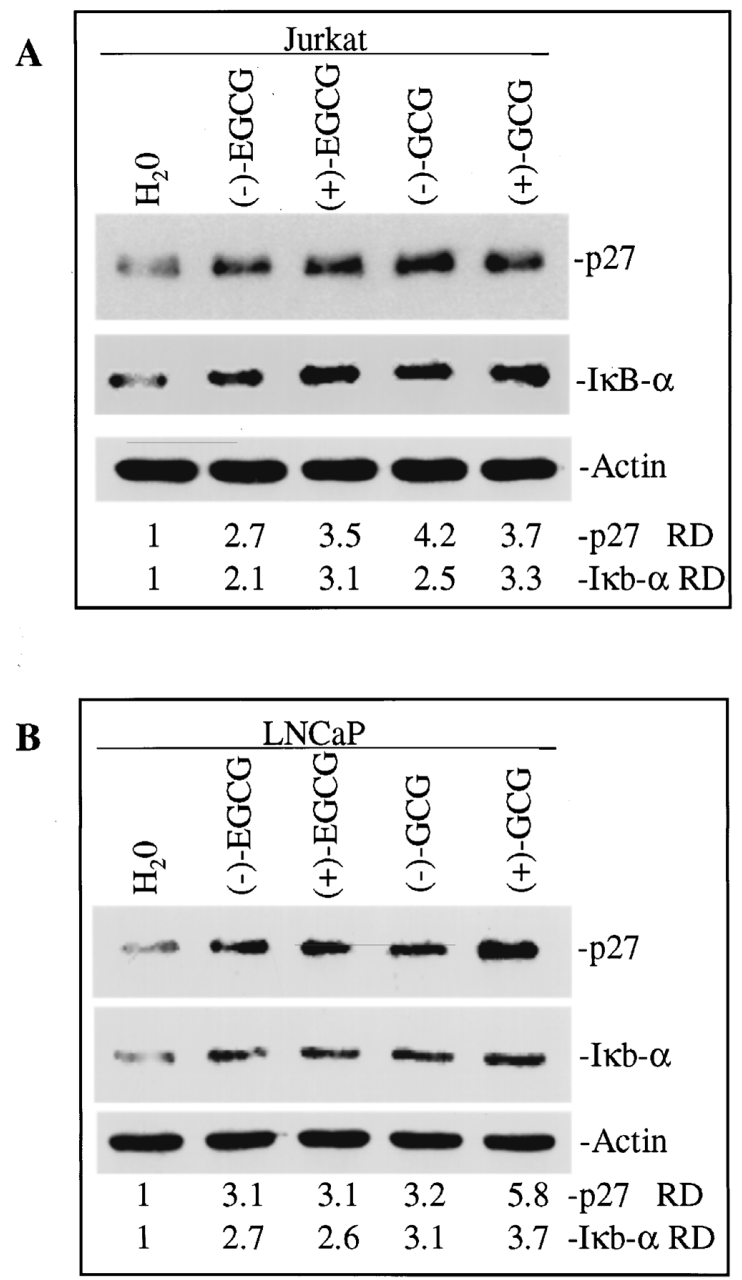

Fig. 4. Accumulation of p27 and $\mathrm{I} \kappa \mathrm{B}-\alpha$ proteins by synthetic and natural GTPs. Jurkat $\mathrm{T}$ (A) and prostate cancer LNCaP (B) cells were incubated for $12 \mathrm{hr}$ with either solvent $\left(\mathrm{H}_{2} \mathrm{O}\right)$ or $10 \mu \mathrm{M}$ indicated GTP, followed by a Western blot assay using specific antibodies to p27, I $\kappa \mathrm{B}-\alpha$, or actin (a loading control). Molecular masses of $\mathrm{I} \kappa \mathrm{B}-\alpha$ and actin are 40 and $43 \mathrm{kDa}$, respectively. Relative Density (RD) values are normalized ratios of the intensities of p27 and $\mathrm{I} \kappa \mathrm{B}-\alpha$ band to the corresponding actin band. Data is representative of at least three independent experiments.

The above experiment was also performed in prostate cancer LNCaP cells. The synthetic (+)-EGCG increased the levels of p27 and $\mathrm{I} \kappa \mathrm{B}-\alpha$ by 3.1- and 2.6fold, respectively, comparable to the effects of $(-)$ EGCG (Fig. 4B). A 5.8- and 3.7-fold increase in p27 and $\mathrm{I} \kappa \mathrm{B}-\alpha$ levels, respectively, was observed after treatment with (+)-GCG (Fig. 4B). The control compound (-)-GCG did not accumulate as much p27 protein as the synthetic compound did, although both compounds accumulated similar levels of $\mathrm{I} \kappa \mathrm{B}-\alpha$ (Fig. 4B).

It has been shown that overexpression of p27 $(42,43)$ and $I \kappa B-\alpha(44,45)$ results in $G_{1}$ arrest. If increased levels of these proteasome target proteins by synthetic GTPs are functional, we would expect to see growth arrest of tumor cells in $G_{1}$ phase. 


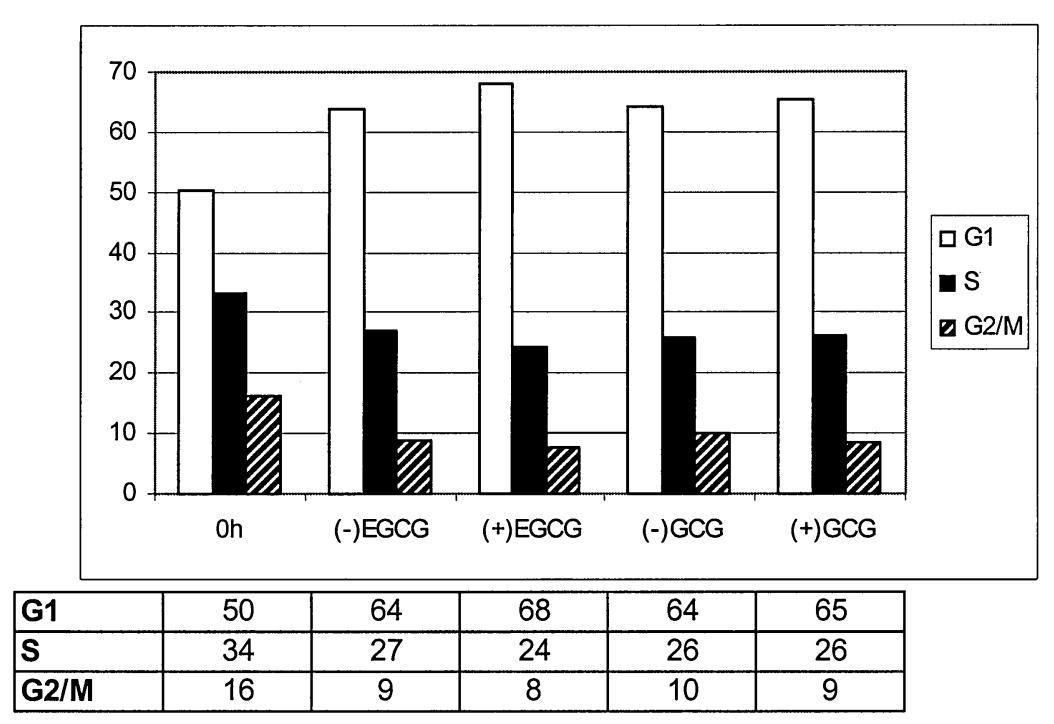

Fig. 5. Synthetic GTPs induces $G_{1}$ arrest in prostate cancer LNCaP cells. Asynchronous prostate LNCaP tumor cells were treated for $24 \mathrm{hr}$ with either solvent ( $C$ for control) or $10 \mu \mathrm{M}$ of the indicated GTP. Cells were then harvested, and analyzed by flow cytometry (see Materials and Methods for details). The amount of $G_{1}, S$ and $G_{2} / M$ cell populations was demonstrated by DNA histogram. Growth arrest is determined by the increase in the percentage of the $G_{1}$ population. Data is representative of at least three independent experiments.
To test this hypothesis, LNCaP cells were treated with $10 \mu \mathrm{M}$ of synthetic (+)-EGCG and (+)-GCG, along with each respective natural GTP as control, for $24 \mathrm{~h}$, followed by cell cycle analysis by flow cytometry. It was observed that treatment with each of the GTPs significantly increase the $G_{1}$ population, accompanied by a reduction in $S$ and $G_{2} / M$ phase cell populations. Specifically, the synthetic $(+)$-EGCG increased the $G_{1}$ population by $18 \%$, while (-)-EGCG, (+)-GCG and (-)-GCG all induced $\sim 14 \% G_{1}$ arrest (Fig. 5). Therefore, the synthetic GTPs have the ability to inhibit prostate tumor cell growth, with potency either similar to, or even greater than, that of the natural compounds.

\section{Accumulation of the Pro-apoptotic Bax Protein} and Activation of Tumor Cell Apoptotic Program by Synthetic GTPS

The pro-apoptotic protein Bax is another target protein of the proteasome $(28,39)$. To investigate whether synthetic tea polyphenols have the ability to induce Bax-associated cancer cell apoptosis, we used two human prostate cancer cell lines, LNCaP and DU145. It has been shown previously that LNCaP cells express much higher levels of Bax protein than DU145 cells (46-48). The comparison between these two cell lines provides an excellent model for studying the role of Bax in the process of GTP-mediated proteasome inhibition and apoptosis induction.

Indeed, we also observed high Bax protein levels in LNCaP cells, and very low Bax expression in DU 145 cells (Fig. 6A). Treatment of LNCaP cells for $24 \mathrm{~h}$ with synthetic $(+)$-EGCG at $10 \mu \mathrm{M}$ significantly increased Bax protein levels, similar to the effect of the natural (-)-EGCG (Fig. 6B). In contrast, neither $(+)$-EGCG nor $(-)$-EGCG was able to increase the levels of Bax protein in DU145 cells.

To examine whether (+)-EGCG could induce apoptosis only in LNCaP, but not DU-145, cells, both cell lines were treated with $10 \mu \mathrm{M}(+)$-EGCG for 24,48 or $72 \mathrm{~h}$, followed by performance of cellfree caspase-3 activity assay. (+)-EGCG activated caspase- 3 in LNCaP cells in a time-dependent manner: by $2.5-, 3.5-$ and 6 -fold at 24,48 and $72 \mathrm{~h}$, respectively (Fig. 6C). In contrast, little caspase-3 activity was detected in (+)-EGCG-treated in DU145 cells: only $\sim 2$-fold induction at $72 \mathrm{~h}$ (Fig. $6 \mathrm{C}$ ). In the same experiment, (-)-EGCG at $10 \mu \mathrm{M}$ was used as a control. We found that the potency of $(+)$ EGCG to activate caspase- 3 was comparable to that of (-)-EGCG in both LNCaP and DU145 cells (Fig. 6C). Consistent with that finding, (+)-EGCG, as well as (-)-EGCG, induced the apoptosisspecific PARP cleavage only in LNCaP, but not DU145 cells (Fig. 6D). Therefore, the abilities of $(+)$-EGCG to activate apoptotic program in these prostate cancer cell lines are correlated well to their abilities to accumulate Bax protein levels to a critical high threshold (compare Fig. 6C-D vs. B). These data suggest that EGCG accumulated Bax protein plays an essential role in activating caspases and inducing apoptosis in human prostate cancer cells.

\section{Inhibition of Colony Formation in Soft Agar Assay by Synthetic GTPs}

Thus far, we have demonstrated that synthetic GTPs can inhibit the proteasome in its purified $20 \mathrm{~S}$ form, in cell extracts, and in intact Jurkat and LNCaP cells, and that inhibition of tumor cell proteasome activity by synthetic GTPs is associated with induction of growth arrest or apoptosis (Figs. 2-6). We then wanted to test the in vivo effects of the synthetic GTPs in soft agar, an assay that mimics tumor growth in tissue. LNCaP cells were plated in soft agar (see Materials and Methods) along with $10 \mu \mathrm{M}$ of each indicated GTP or solvent $\left(\mathrm{H}_{2} \mathrm{O}\right)$, followed by a 14 day-incubation to allow for colony formation (Fig. 7). The solvent-treated plates allowed for the development of $\sim 1,400$ colonies, while synthetic 
$\mathbf{A}$

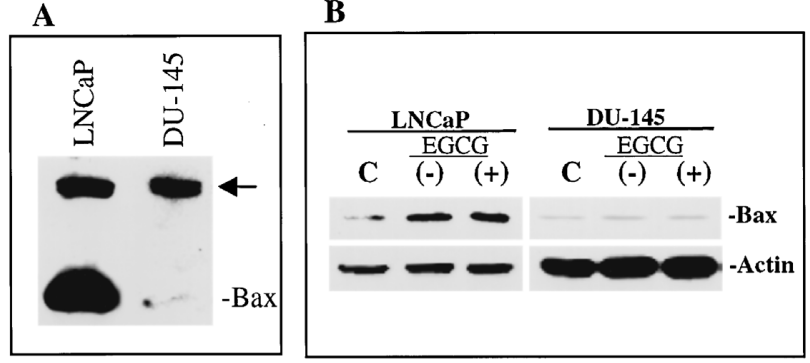

C

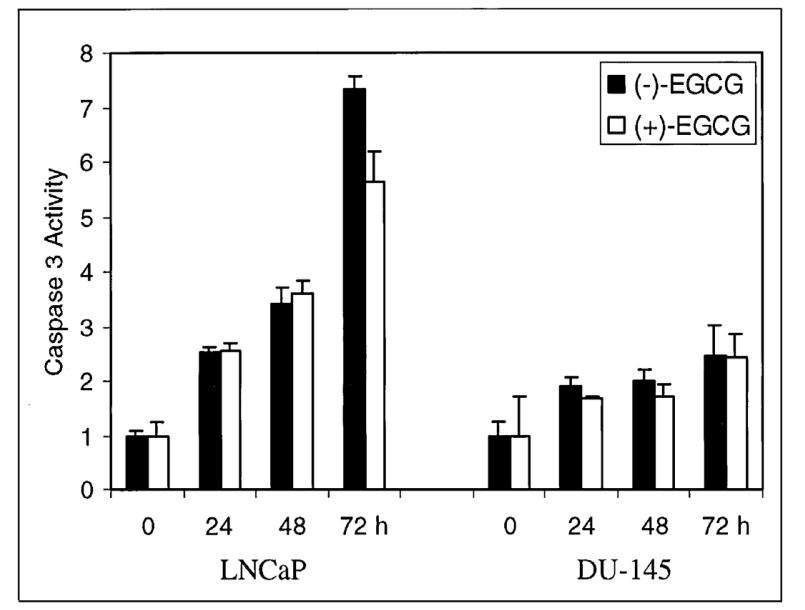

D

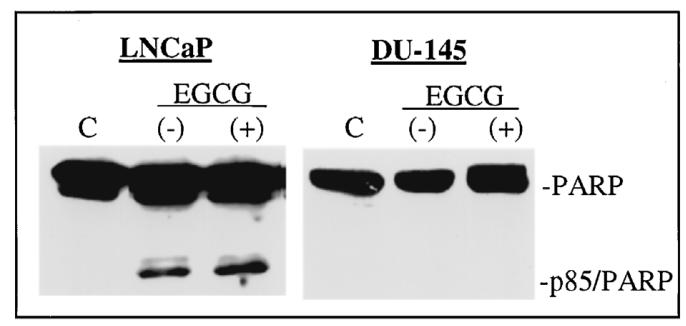

Fig. 6. Induction of Bax-associated apoptosis by synthetic and natural GTPs. Exponentially growing LNCaP and DU-145 prostate cells were harvested and the levels of Bax protein was detected by Western blotted analysis (A). Bax (21 kD) is indicated. A high-molecular-weight band, recognized by the anti-Bax antibody, is indicated by an arrowhead. Although its nature remains unknown, this high-molecular-weight band can be used as a loading control. LNCaP or DU-145 cells were treated for $24 \mathrm{~h}$ with either $\mathrm{H}_{2} \mathrm{O}(\mathrm{C}$, for control) or $10 \mu \mathrm{M}$ $(-)$-EGCG or $(+)$-EGCG (B). Cells were then harvest and Western-blotted with specific antibodies to Bax, actin (B) or PARP (D). Data are representative of at least three independent experiments. Caspase- 3 activity was determined in LNCaP and DU-145 cells after $0,24,48$, or $72 \mathrm{~h}$ treatment with $10 \mu \mathrm{M}$ $(-)$-EGCG or (+)-EGCG. Cells were harvested at each sequential time-point and activity was determined by incubating whole cell extracts with caspase- 3 substrate and measuring free AMCs (C). All the time-points were normalized to 0 hour. Values are means of triplicate independent experiments and error bars denote standard deviations.

$(+)$-EGCG treatment abolished formation of nearly all the colonies (99.5\% inhibition), similar to the natural (-)-EGCG (99.0\% inhibition; Fig. 7A-B). As expected, the inactive synthetic Bn-(+)-EGCG, which cannot inhibit the proteasome activity (Figs. 2-3), had little inhibitory activity on colony formaiton $(\sim 10 \%$ inhibition). The synthetic (+)-GCG compound was
A

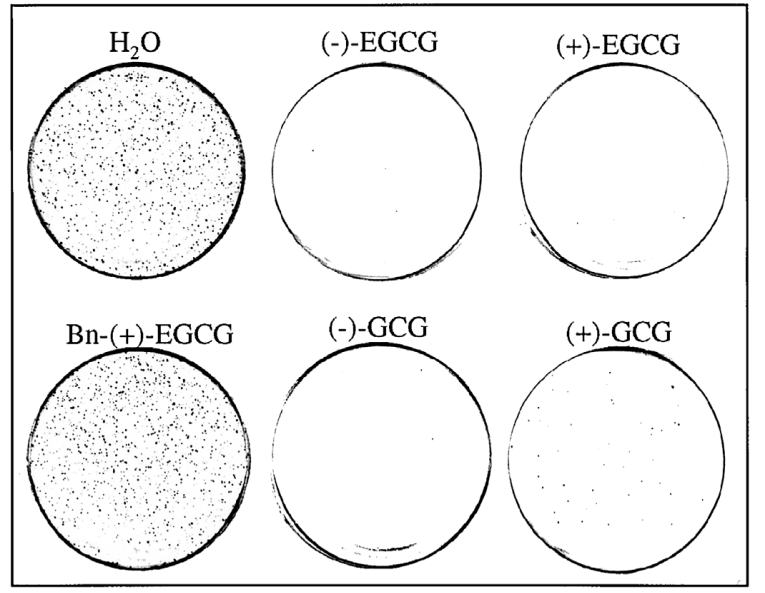

B

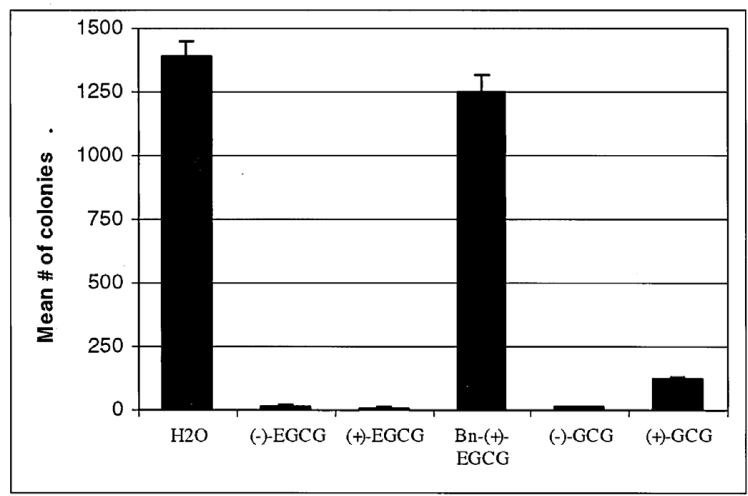

Fig. 7. Synthetic GTPs inhibit soft agar colony formation. Prostate LNCaP tumor cells were plated in soft agar with the solvent $\mathrm{H}_{2} \mathrm{O}$ or $10 \mu \mathrm{M}$ of the indicated GTP as described in the Materials and Methods. Cells were then cultured for 14 days without addition of new drug. A representative plate from each treatment was scanned and selected for presentation (A). Colonies were quantified with an automated counter and presented as mean values from triplicate independent experiments. Error bars denote standard deviations.

found to inhibit $91.5 \%$ of colony formations, however, it was not as potent as the synthetic (+)-EGCG or the natural (-)-GCG (99\% inhibition, Fig. 7A-B). These data demonstrate that synthetic GTPs, especially $(+)-$ EGCG, can inhibit prostate cancer cell growth and colony formation in a semi-in situ assay.

\section{Discussion}

There is currently a large amount of literature describing the different anti-cancer mechanisms of natural tea polyphenols. Sorting out the anti-cancer mechanisms that are indeed responsible for the observed epidemiological and animal study effects of tea could be a daunting task. We believe the first criteria for sorting out these mechanisms is to select mechanistic activities that occur at concentrations at or near the observed physiological concentrations of GTPs (15). The physiological concentration of a single GTP (such as EGCG) has been observed to be in the single digit $\mu \mathrm{M}$ to high nanomolar ranges $(49,50)$. 
Therefore, if a GTP of interest is to function physiologically, the mechanism of action must therefore occur at concentrations similar to those found for GTPs in serum.

Synthesis of GTP analogs should also prove beneficial for determining which mechanisms are responsible for the observed anti-cancer effects. For example, it is possible that the kinase-inhibitory activity of EGCG (11-13) could be removed in some EGCG analogs while retaining the proteasomeinhibitory activities, and vice-versa. These synthetic GTP analogs could therefore help to solve the problem of distinguishing the important mechanistic properties of tea polyphenols.

The work presented here demonstrates, for the first time, that synthetic GTPs are active and comparable to their natural counterparts in biological assays. The proteasome-inhibitory potency of the synthetic (+)-EGCG was found to be similar to, and sometimes higher than, that of the natural stereoisomer (-)-EGCG (Figs. 2-7). A similar characteristic was also found for the $(+)$-GCG compound and its control (-)-GCG. However, the benzyl-protected compound, Bn-(+)-EGCG, which has no available hydroxyls for hydrogen binding, can not inhibit the proteasome despite the presence of the ester-bond that is susceptible to a nucleophilic attack by the proteasome's N-terminal threonine (15). This suggests that hydrogen bonding to some or all of EGCG's eight $\mathrm{OH}$ groups are important in binding to the proteasome active site for inhibition. However, introduction of eight such benzyl groups would also no doubt add a lot of mass to EGCG as well as cause other steric difficulties during proteasomal binding in addition to the elimination of hydrogen bonding potentials.

The aforementioned experiments demonstrate that the synthetic enantiomers of these two GTPs, $(+)$-EGCG and (+)-GCG, at least did not loose any, and even may have gained some potency in regards to proteasome inhibition. Figure 3 also demonstrates that the specificity profile is also the same in regards to three different protease activities: chymotrypsin-like, trypsin-like, and calpain. This at least suggests that the synthetic stereoisomers are inhibiting via a similar mechanism as the natural occurring compounds. Normally, most biological processes show chiral discrimination, where enantiomers display different biological activities. While it is too early to speculate on the reason for the lack of chiral discrimination in the present case, an argument can be made that the presence of the two trihydroxyphenyl rings in EGCG (or GCG) may have rendered the molecule pseudo-symmetric in terms of its binding to the active site of proteasome.

It has been suggested that under in vivo conditions, GTPs, specifically (-)-EGCG, are unstable and can be degraded or altered, quickly making them unavailable for inhibition of enzymatic activities $(15,50,51)$. It was then thought that synthetic GTPs might have identical potencies as natural ones, but with increased stability. To test this idea synthetic and natural GTP compounds were used in both suspension (Jurkat) and solid tumor (LNCaP) cell lines to determine their ability to accumulate proteins that are degraded by the proteasome. In Jurkat cells this hypothesis seemed at least partially fulfilled because there was nearly a $30 \%$ increase in p27 levels and a $47 \%$ increase in $\mathrm{I} \kappa \mathrm{B}-\alpha$ levels in cells treated with (+)-EGCG, as compared to (-)-EGCG (Fig. 4A). However, the accumulation of p27 and $\mathrm{I} \kappa \mathrm{B}-\alpha$ levels in LNCaP cells was nearly identical for both $(+)$-EGCG as well as (-)-EGCG (Fig. 4B). The (+)-GCG compound also increased the levels of both proteins to higher levels in both cell lines as compared to the (-)GCG compound, except p27 in Jurkat cells (Fig. 4). Though these differences are marginal it at least suggest the possibility that synthetic enantiomers may have better effects in animal models and clinical trials than do their natural counterparts, possibly due to an increase in drug stability in vivo.

In agreement with p27 and I $\kappa \mathrm{B}-\alpha$ accumulation in the in vivo experiments, cell cycle arrest was also observed after LNCaP cells were treated with these GTPs. Again, (+)-EGCG was found to be the most potent compound and induced an $18 \% \mathrm{G}_{1}$ arrest, compared to the positive control (-)-EGCG which induced $14 \% G_{1}$ arrest, an approximately $30 \%$ increase just by changing the stereochemistry of the natural compound (Fig. 5). This again could suggest an increased stability of the synthetic compound might be responsible for increased ability to induce growth arrest.

To better determine whether these synthetic compounds induce Bax-dependent apoptosis, a pair of prostate cancer cell lines with either high or low Bax protein expression were used. It has been demonstrated that proteasome inhibitors can induce tumor cell death via accumulation of the pro-apoptotic Bcl-2 family member Bax (28). GTPs have been shown to induce apoptosis (52-55) so we hypothesized that the synthetic EGCG analog should be able to accumulate levels of Bax and induce apoptosis in LNCaP cells which contain high basal leveles of Bax, but should not induce apoptosis in DU-145 cells which express low Bax protein. Indeed, when these two prostate cancer cell lines were treated with either $(+)$-EGCG or natural (-)-EGCG, apoptosis was induced by both compounds in LNCaP cells but not in DU- 145 cells, as judged by caspase- 3 activation and PARP cleavage (Fig. 6). This suggests that the synthetic EGCG analog can induce apoptosis in a Baxdependant manner, supporting the conclusion that apoptosis would have been initiated via inhibition of proteasome-mediated Bax degradation.

The desired effect of any anti-tumor compound including cancer-preventative agents is to inhibit tumor growth and formation in situ. An assay developed to semi-mimic cellular growth in tissue is the colony forming soft agar assay. We hypothesized that 
the synthetic GTPs that can inhibit the proteasome activity and cell cycle progression as well as induce cell death should be able to inhibit colony formation in a soft agar assay. Indeed, when LNCaP tumor cells were cultured in the presence of synthetic GTPs, an almost complete inhibition of colony formation was observed, as compared to the solvent control and the inactive Bn-(+)-EGCG (Fig. 7). This demonstrates that usage of these synthetic GTPs in future animal studies and in clinical trials at this stage looks promising.

Inhibition of the proteasomal activity by tea polyphenols is a new mechanism for the explanation of anti-cancer activities associated with tea. Synthetic analogs of natural tea polyphenols should help to create more potent or stable compounds for the prevention and treatment of cancer. Many of the current chemotherapeutic drugs were developed by leads from natural products, and we believe that the research presented here is the initial development for such novel, potentially successful cancer-preventive drugs.

\section{Acknowledgments}

This work is supported in part by research grants from the National Cancer Institute-National Institutes of Health, the United States Army Medical Research and Material Commend, and H. Lee Moffitt Cancer Center \& Research Institute (to Q. P. D.) and the Natural Science and Engineering Research Council of Canada (to T. H. C.). We thank the Flow Cytometry and Molecular Imaging Facilities at $\mathrm{H}$. Lee Moffitt Cancer Center $\delta$ Research Institute for supporting this research.

\section{References}

1. Ohno Y, Wakai K, Genka K, et al. (1995) Tea consumption and lung cancer risk: a case-control study in Okinawa, Japan. Jpn. J. Cancer Res. 86: 1027-1034.

2. Ji BT, Chow WH, Hsing AW, et al. (1997) Green tea consumption and the risk of pancreatic and colorectal cancers. Int. J. Cancer 70: 255-258.

3. Mendilaharsu M, De Stefani E, Deneo-Pellegrini $H$, et al. (1998) Consumption of tea and coffee and the risk of lung cancer in cigarette-smoking men: a case-control study in Uruguay. Lung Cancer 19: 101-107.

4. Chow WH, Swanson CA, Lissowska J, et al. (1999) Risk of stomach cancer in relation to consumption of cigarettes, alcohol, tea and coffee in Warsaw, Poland. Int. J. Cancer 81: 871-876.

5. Zhong L, Goldberg MS, Gao YT, et al. (2001) A populationbased case-control study of lung cancer and green tea consumption among women living in Shanghai, China. Epidemiology 12: 695-700.

6. Inoue M, Tajima K, Mizutani M, et al. (2001) Regular consumption of green tea and the risk of breast cancer recurrence: follow-up study from the Hospital-based Epidemiologic Research Program at Aichi Cancer Center (HERPACC), Japan. Cancer Lett. 167: 175-182.

7. Nishida H, Omori M, Fukutomi Y, et al. (1994) Inhibitory effects of $(-)$-epigallocatechin gallate on spontaneous hepatoma in $\mathrm{C} 3 \mathrm{H} / \mathrm{HeNCrj}$ mice and human hepatomaderived PLC/PRF/5 cells. Jpn. J. Cancer Res. 85: 22 1-225.
8. Liao S, Umekita Y, Guo J, et al. (1995) Growth inhibition and regression of human prostate and breast tumors in athymic mice by tea epigallocatechin gallate. Cancer Lett. 96: 239-243.

9. Chung FL. (1999) The prevention of lung cancer induced by a tobacco-specific carcinogen in rodents by green and black Tea. Proc. Soc. Exp. Biol. Med. 220: 244-248.

10. Mimoto J, Kiura K, Matsuo K, et al. (2000) (-)-Epigallocatechin gallate can prevent cisplatin-induced lung tumorigenesis in A/J mice. Carcinogenesis 21: 915-919.

11. Masuda M, Suzui M and Weinstein IB. (2001) Effects of epigallocatechin-3-gallate on growth, epidermal growth factor receptor signaling pathways, gene expression, and chemosensitivity in human head and neck squamous cell carcinoma cell lines. Clin. Cancer Res. 7: 4220-4229.

12. Yu R, Jiao JJ, Duh JL, et al. (1997) Activation of mitogenactivated protein kinases by green tea polyphenols: potential signaling pathways in the regulation of antioxidantresponsive element-mediated phase II enzyme gene expression. Carcinogenesis 18: 451-456.

13. Chung JY, Park JO, Phyu H, et al. (2001) Mechanisms of inhibition of the Ras-MAP kinase signaling pathway in 30.7b Ras 12 cells by tea polyphenols (-)-epigallocatechin-3-gallate and theaflavin-3, 3'-digallate. FASEB J. 15: 2022-2024.

14. Naasani I, Seimiya H, Tsuruo T. (1998) Telomerase inhibition, telomere shortening, and senescence of cancer cells by tea catechins. Biochem. Biophys. Res. Commun. 249: 391-396.

15. Nam S, Smith DM, Dou QP. (2001) Ester bond-containing tea polyphenols potently inhibit proteasome activity in vitro and in vivo. J. Biol. Chem. 276: 13322-13330.

16. Yu GP, Hsieh CC, Wang LY, et al. (1995) Green-tea consumption and risk of stomach cancer: a population-based casecontrol study in Shanghai, China. Cancer Causes Control 6: 532-538.

17. Zheng W, Doyle TJ, Kushi LH, et al. (1996) Tea consumption and cancer incidence in a prospective cohort study of postmenopausal women. Am. J. Epidemiol. 144: 175-182.

18. Fujiki H. (1999) Two stages of cancer prevention with green tea. J. Cancer Res. Clin. Oncol. 125: 589-597.

19. Suganuma M, Okabe S, Sueoka N, et al. (1999) Green tea and cancer chemoprevention. Mutat Res 428: 339-344.

20. Fujiki H, Suganuma M, Okabe S, et al. (2000) A new concept of tumor promotion by tumor necrosis factor-alpha, and cancer preventive agents (-)-epigallocatechin gallate and green tea-a review [In Process Citation]. Cancer Detect. Prev. 24: 91-99.

21. Mukhtar H, Ahmad N. (2000) Tea polyphenols: prevention of cancer and optimizing health. Am. J. Clin. Nutr. 71: 1698S-1702S (discussion 1703S-1694S).

22. Pisters KM, Newman RA, Coldman B, et al. (2001) Phase I trial of oral green tea extract in adult patients with solid tumors. J. Clin. Oncol. 19: 1830-1838.

23. Chow HH, Cai Y, Alberts DS, et al. (2001) Phase I pharmacokinetic study of tea polyphenols following single-dose administration of epigallocatechin gallate and polyphenon E. Cancer Epidemiol. Biomarkers Prev. 10: 53-58.

24. Dou QP and Li B. (1999) Proteasome inhibitors as potential novel anticancer agents. Drug Resist. Updat. 2: 215-223.

25. An B, Goldfarb RH, Siman R, Dou QP. (1998) Novel dipeptidyl proteasome inhibitors overcome Bcl-2 protective function and selectively accumulate the cyclin-dependent kinase inhibitor p27 and induce apoptosis in transformed, but not normal, human fibroblasts. Cell Death Differ. 5: 10621075.

26. Grimm LM, Goldberg AL, Poirier GG, et al. (1996) Proteasomes play an essential role in thymocyte apoptosis. Embo. J. 15: 3835-3844.

27. Lee DH, Goldberg AL. (1998) Proteasome inhibitors: valuable new tools for cell biologists. Trends Cell Biol. 8: 397-403.

28. Li B, Dou QP. (2000) Bax degradation by the ubiquitin/ proteasome-dependent pathway: involvement in tumor survival and progression. Proc. Natl. Acad. Sci. USA 97: $3850-3855$. 
29. Adams J. (2001) Proteasome inhibition in cancer: development of PS-341. Semin. Oncol. 28: 613-619.

30. Hideshima T, Richardson P, Chauhan D, et al. (2001) The proteasome inhibitor PS-341 inhibits growth, induces apoptosis, and overcomes drug resistance in human multiple myeloma cells. Cancer Res. 61: 3071-3076.

31. Adams J, Palombella VJ, Sausville EA, et al. (1999) Proteasome inhibitors: a novel class of potent and effective antitumor agents. Cancer Res. 59: 2615-2622.

32. Sun J, Nam S, Lee CS, et al. (2001) CEP1612, a dipeptidyl proteasome inhibitor, induces p2lWAFl and p27KIP1 expression and apoptosis and inhibits the growth of the human lung adenocarcinoma A-549 in nude mice. Cancer Res. 61: 1280-1284.

33. Cusack, Jr JC, Liu R, Houston M, et al. (2001) Enhanced chemosensitivity to CPT-11 with proteasome inhibitor PS-341: implications for systemic nuclear factor-kappaB inhibition. Cancer Res. 61: 3535-3540.

34. Thompson JE, Phillips RJ, Erdjument-Bromage $\mathrm{H}$, et al. (1995) I kappa B-beta regulates the persistent response in a biphasic activation of NF-kappa B. Cell 80: 573-582.

35. Perkins ND. (2000) The Rel/NF-kappa B family: friend and foe. Trends Biochem. Sci. 25: 434-440.

36. Palombella VJ, Rando OJ, Goldberg AL, Maniatis T. (1994) The ubiquitin-proteasome pathway is required for processing the NF-kappa Bl precursor protein and the activation of NFkappa B. Cell 78: 773-785.

37. Nam S, Smith D and Dou Q. (2001) Tannic acid potently inhibits tumor cell proteasome activity, increases p27 and Bax expression, and induces $\mathrm{G}_{1}$ arrest and apoptosis. Cancer Epidemiol. Biomarkers Prev. 10: 1083-1088.

38. Green DR, Reed JC. (1998) Mitochondria and apoptosis. Science 281: 1309-1312.

39. Chang YC, Lee YS, Tejima T, et al. (1998) mdm2 and bax, downstream mediators of the $\mathrm{p} 53$ response, are degraded by the ubiquitin-proteasome pathway. Cell Growth Differ. 9: 79-84.

40. Li L, Chan TH. (2001) Enantioselective synthesis of epigallocatechin-3-gallate (EGCG), the active polyphenol component from green tea. Org. Lett. 3: 739-741.

41. Menter DG, Sabichi AL and Lippman SM. (2000) Selenium effects on prostate cell growth. Cancer Epidemiol Biomarkers Prev 9: 1171-1182.

42. Polyak K, Lee MH, Erdjument-Bromage H, et al. (1994) Cloning of p27Kip 1, a cyclin-dependent kinase inhibitor and a potential mediator of extracellular antimitogenic signals. Cell 78: $59-66$.
43. Toyoshima H, Hunter T. (1994) p27, a novel inhibitor of G1 cyclin-Cdk protein kinase activity, is related to p2 1 . Cell 78: $67-74$.

44. Hinz M, Krappmann D, Eichten A, et al. (1999) NF-kappaB function in growth control: regulation of cyclin $\mathrm{D}$ l expression and G0/Gl-to-S-phase transition. Mol. Cell Biol. 19: $2690-2698$.

45. Guttridge DC, Albanese C, Reuther JY, et al. (1999) NF-kappaB controls cell growth and differentiation through transcriptional regulation of cyclin Dl. Mol. Cell Biol. 19: 5785-5799.

46. Haldar S, Chintapalli J, Croce CM. (1996) Taxol induces bcl-2 phosphorylation and death of prostate cancer cells. Cancer Res. 56: 1253-1255.

47. Rokhlin OW, Glover RA, Cohen MB. (1998) Fas-mediated apoptosis in human prostatic carcinoma cell lines occurs via activation of caspase-8 and caspase-7. Cancer Res. 58: $5870-5875$.

48. Tang DG, Li L, Chopra DP, Porter AT. (1998) Extended survivability of prostate cancer cells in the absence of trophic factors: increased proliferation, evasion of apoptosis, and the role of apoptosis proteins. Cancer Res. 58: $3466-3479$.

49. Nakagawa K, Miyazawa T. (1997) Chemiluminescence-highperformance liquid chromatographic determination of tea catechin, (-)-epigallocatechin 3-gallate, at picomole levels in rat and human plasma. Anal. Biochem. 248: 41-49.

50. Van Amelsvoort JM, Van Hof KH, Mathot JN, et al. (2001) Plasma concentrations of individual tea catechins after a single oral dose in humans. Xenobiotica 31: 891-901.

51. Li C, Lee MJ, Sheng S, et al. (2000) Structural identification of two metabolites of catechins and their kinetics in human urine and blood after tea ingestion. Chem. Res. Toxicol. 13: 177-184.

52. Smith DM, Dou QP. (2001) Green tea polyphenol epigallocatechin inhibits DNA replication and consequently induces leukemia cell apoptosis. Int. J. Mol. Med. 7: 645-652.

53. Yang GY, Liao J, Kim K, et al. (1998) Inhibition of growth and induction of apoptosis in human cancer cell lines by tea polyphenols. Carcinogenesis 19: 611-616.

54. Ahmad N, Feyes DK, Nieminen AL, et al. (1997) Green tea constituent epigallocatechin-3-gallate and induction of apoptosis and cell cycle arrest in human carcinoma cells. J. Natl. Cancer Inst. 89: 1881-1886.

55. Paschka AG, Butler R, Young CY. (1998) Induction of apoptosis in prostate cancer cell lines by the green tea component, (-)-epigallocatechin-3-gallate. Cancer Lett. 130: 1-7. 